\title{
Evidence for increased expression of tissue factor and protease- activated receptor-1 in human esophageal cancer
}

\author{
FABIANA S. RIBEIRO ${ }^{1,2}$, TATIANA A. SIMÃO ${ }^{1}$, NIVEA D. AMOÊDO ${ }^{2}$, NELSON A. ANDREOLLO ${ }^{3}$, \\ LUIZ ROBERTO LOPES ${ }^{3}$, RODOLFO ACATAUASSU ${ }^{4}$, FRANKLIN D. RUMJANEK ${ }^{2}$, \\ RODOLPHO M. ALBANO ${ }^{1}$, LUIS FELIPE R. PINTO ${ }^{1}$ and ROBSON Q. MONTEIRO ${ }^{2}$ \\ ${ }^{1}$ Departamento de Bioquímica, IBRAG, Universidade do Estado do Rio de Janeiro, RJ; ${ }^{2}$ Instituto de \\ Bioquímica Médica, Universidade Federal do Rio de Janeiro, RJ; ${ }^{3}$ Departamento de Cirurgia e Gastrocentro, \\ Faculdade de Ciências Médicas, Universidade Estadual de Campinas, SP; ${ }^{4}$ Serviço de Cirurgia Torácica, \\ Hospital Universitário Pedro Ernesto, Universidade do Estado do Rio de Janeiro, RJ, Brazil
}

Received December 10, 2008; Accepted February 27, 2009

DOI: 10.3892/or_00000393

\begin{abstract}
It has been suggested that the blood clotting initiator protein, tissue factor (TF), participates in tumor growth, metastasis and angiogenesis. In addition, a family of $\mathrm{G}$ protein-coupled-receptors known as protease-activated receptors (PARs) has also been implicated in tumor biology. These receptors might be activated by blood coagulation proteases thus eliciting a number of pro-tumoral responses, including the expression of interleukin-8 (IL-8). Therefore, in this study we analyzed the expression of TF, PAR-1, PAR-2 and IL- 8 genes in patients with esophageal cancer, one of the most aggressive neoplastic diseases. Total RNA was extracted from tissue samples (tumor and the corresponding normal mucosa) obtained from patients submitted to esophagectomy or endoscopy and further analyzed by semi-quantitative reverse transcriptase-polymerase (RT-PCR) and/or real-time quantitative PCR (qPCR). Expression of fulllength transmembrane TF was significantly higher in tumor samples whereas no differences were observed in alternatively spliced TF transcripts. Tumor tissue showed increased mRNA levels for PAR-1 but not PAR-2. Remarkably, IL-8 expression was not detected in most normal tissues but showed very high expression in tumor samples. As expected, qPCR revealed greater differences in the expression pattern of all transcripts analyzed but the general profile was very
\end{abstract}

Correspondence to: Dr Robson Q. Monteiro, Universidade Federal do Rio de Janeiro, Instituto de Bioquímica Médica/CCS, Av. Carlos Chagas Filho 373, Cidade Universitária, Ilha do Fundão, Rio de Janeiro, RJ 21941-590, Brazil

E-mail: robsonqm@bioqmed.ufrj.br

Key words: esophageal squamous cell carcinoma, clotting initiator tissue factor, protease activated receptor- 1 , interleukin- 8 similar to that observed by RT-PCR. Altogether our data suggest a possible role for blood clotting proteins in the biology of human esophageal cancer.

\section{Introduction}

Esophageal cancer is the eighth most common cancer in the world and its overall incidence rate is 2 -fold higher in less-developed compared with more-developed geographic regions (1). Brazil presents one of the highest incidence areas in the West, being esophageal cancer the fourth most fatal malignancy among men and the sixth among women (2). The main histological types of esophageal cancer are squamous cell carcinoma (ESCC) and adenocarcinoma. ESCC is estimated to account for around $90 \%$ of esophageal cancers but the frequency of adenocarcinoma has been continuously increasing, especially in Western populations $(3,4)$. Despite advances in multimodality therapy, the prognosis for patients with ESCC still remains poor, with an average 5-year survival rate $<10 \%$ due to difficulties in early diagnosis and treatment (5-6).

An association between thrombosis and cancer has long been described (7). In fact, the mechanisms that link thrombosis and cancer involve a complex interaction between tumor and host cells as well as the hemostatic system (7-8). In the last few years, it has become clear that the processes of cancer metastasis and invasion are highly dependent on components of the blood coagulation cascade. In this regard, tissue factor (TF), the physiological initiator of coagulation, has been reported as a key determinant of the coagulation/cancer interaction (8). TF expression has been shown to correlate with the histological grade of malignancy of several types of cancer, being particularly associated with tumor dissemination and angiogenesis (9-12).

In addition to $\mathrm{TF}$, a family of $\mathrm{G}$ protein-coupled receptors known as protease-activated receptors (PARs) has been implicated in tumor biology (13). These receptors might be activated through proteolytic cleavage by blood coagulation enzymes thus eliciting the production of several pro-tumoral factors including cytokines, angiogenic factors and metallo- 
Table I. Sequence of primers and conditions used for RT-PCR.

\begin{tabular}{|c|c|c|c|c|c|}
\hline Gene & Accession no. ${ }^{\mathrm{a}}$ & Primers sequences $\left(5^{\prime}-3^{\prime}\right)$ & Product $(b p)^{b}$ & $\begin{array}{c}\text { Annealing } \\
\text { temperature }\left({ }^{\circ} \mathrm{C}\right)\end{array}$ & Cycle \\
\hline asTF & NM_001993.3 & $\begin{array}{l}\text { F: ACCGACGAGATTGTGAAGGATGT } \\
\text { R: TCAAAAGTCCACCCAGGATTT }\end{array}$ & 815 & 63 & 35 \\
\hline flTF & NM_001993.3 & $\begin{array}{l}\text { F: ACCGACGAGATTGTGAAGGATGT } \\
\text { R: TCAAAAGTCCACCCAGGATTT }\end{array}$ & 972 & 63 & 35 \\
\hline PAR-1 & NM_001992.3 & $\begin{array}{l}\text { F: GCCGCCTGCTTCAGTCTGTGC } \\
\text { R: GGCCAGACAAGTGAAGGAAGC }\end{array}$ & 648 & 67 & 37 \\
\hline PAR-2 & NM_005242.3 & $\begin{array}{l}\text { F: CCATCCAAGGAACCAATAGATC } \\
\text { R: ATGTCTCCCACCAAGAGCTGCTCA }\end{array}$ & 643 & 61 & 35 \\
\hline IL-8 & NM_000584.2 & $\begin{array}{l}\text { F: TGGCTCTCTTGGCAGCCTTC } \\
\text { R: TCTCCACAACCCTCTGCACC }\end{array}$ & 252 & 54 & 30 \\
\hline PCNA & NM_002592.2 & $\begin{array}{l}\text { F: CATCAACGAGGCCTGCTGGGAT } \\
\text { R: CCTAAGATCCTTCTTCATCCTCG }\end{array}$ & 722 & 68 & 30 \\
\hline B-actin & NM_001101.3 & $\begin{array}{l}\text { F: CCTCGCCTTTGCCGATCC } \\
\text { R: GGATCTTCATGAGGTAGTCAGGTC }\end{array}$ & 626 & 55 & 27 \\
\hline
\end{tabular}

${ }^{\mathrm{a}}$ GenBank accession number of corresponding gene available at http://www.ncbi.nlm.nih.gov. ${ }^{\mathrm{b}} \mathrm{PCR}$ product length in base pairs. F, forward primer; R, reverse primer.

proteases among others $(14,15)$. In this context, some studies have demonstrated an increased expression of PAR-1 or PAR-2 in human cancers (16-19).

The aim of this study was to evaluate the expression pattern of TF, PAR-1 and PAR-2 genes in patients with esophageal cancer. Our data demonstrate that TF and PAR-1 transcripts are significantly elevated. Therefore, these proteins might play an important biological role in esophageal cancer and might offer additional strategies for the development of new therapies.

\section{Material and methods}

Human samples. Tumor samples and the corresponding normal mucosa were obtained from 36 patients, 30 males and 6 females, submitted to esophagectomy or endoscopy in three hospitals from the Southern and Southeastern regions of Brazil: Hospital Universitário Pedro Ernesto (RJ), Hospital de Clínicas (RS), and Hospital de Clínicas-Gastrocentro (SP). All collected samples were immediately frozen in liquid nitrogen. All tumor tissues and their adjacent normal epithelia were identified by histopathological analysis. The age of patients ranged from 44 to 83 years (mean 58 years). All individuals who took part in this study signed an informed consent and information was obtained by a standardized questionnaire (approved by the respective Ethics Committees), showed in a previously published study (20), including data on tobacco smoking and alcohol drinking.

RNA extraction. Total RNA was extracted from all samples using the TRIzol ${ }^{\circledR}$ reagent (Invitrogen, USA) following the manufacturer's instructions. All RNA samples were quantified by spectrophotometry and their integrity was evaluated by formaldehyde-agarose gel electrophoresis. The quality of the RNA samples was determined by the ratio of the $28 \mathrm{~S}, 18 \mathrm{~S}$ and 5.8S ribosomal RNA bands and only undegraded RNA was used for reverse transcription (RT) reactions. One to five micrograms of total RNA was used in RT-PCR reactions according to an optimized in situ hot start RT-PCR procedure (21). Equal amount of RNA from the same patient (tumor and normal mucosa) was used in the separate RT reaction.

Semi-quantitative RT-PCR. Primers and PCR conditions used to amplify TF, PAR-1, PAR-2, IL-8, B-actin and PCNA, are shown in Table I. A different number of cycles was tested to determine the linear range of product accumulation for each gene. All PCR experiments were subsequently performed using a number of cycles which allowed a semi-quantitative comparison between samples. PCR reactions were done at least three times for each gene and, when possible, more than one RT reaction was performed for each sample. PCR products were separated by $2 \%$ agarose gel electrophoresis, stained with ethidium bromide, and gel images were digitalized. Band intensities were quantified with LabImage Software (Kapelan $\mathrm{GmbH}$, Germany) and the values obtained for each gene were normalized in relation to the values observed for the amplification of PCNA, to account for the proliferative status of normal and tumor tissues, and for the amplification of the housekeeping gene $\beta$-actin.

Quantitative real-time PCR ( $q P C R)$. Primers used to amplify TF, PAR-1, PAR-2, IL-8 and B-actin are shown in Table II. 
Table II. Sequence of primers and conditions used for qPCR.

\begin{tabular}{llll}
\hline Gene & Accession no. ${ }^{\mathrm{a}}$ & \multicolumn{1}{c}{ Primers sequences $\left(5^{\prime}-3^{\prime}\right)$} & Annealing temperature $\left({ }^{\circ} \mathrm{C}\right)$ \\
\hline TF & NM_001993.3 & F: CAGGCACTACAAATACTGTGG & 60 \\
& R: TGTAGACTTGATTGACGGGTT & 60 \\
PAR-1 & NM_001992.3 & F: GCCAGAATCAAAAGCAACAAA & R: TCATTTTTCTCCTCATCCTCC \\
& NM_005242.3 & F: AGGAACCAGTAGATCCTCTAA & 60 \\
IL-8 & R: AGTGGTCAGTTTTCAGTGAG & 60 \\
B-actin & F: CCAACACAGAAATTATGTAAG & 60 \\
& NM_001101.3 & F: CCAGATCATGTTTGAGACCTT & \\
\hline
\end{tabular}

${ }^{a}$ GenBank accession number of corresponding gene available at http://www.ncbi.nlm.nih.gov. ${ }^{b} P C R$ product length in base pairs. F, forward primer; R, reverse primer.

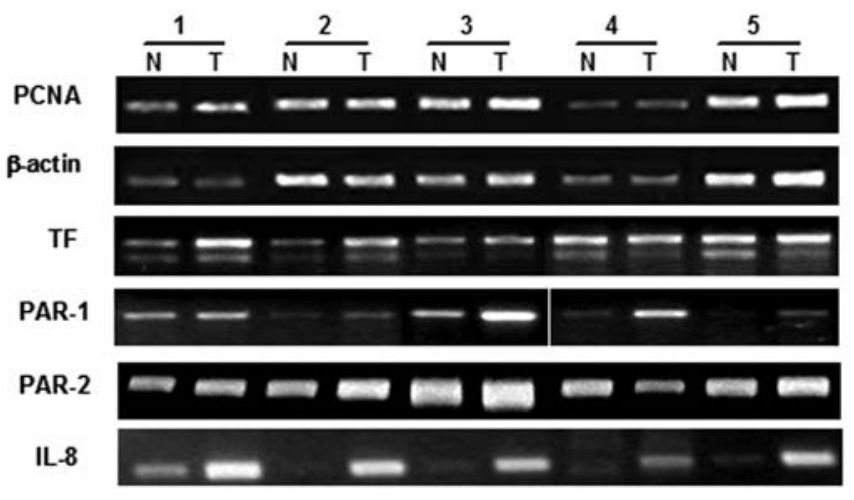

Figure 1. Expression of TF, PAR-1, PAR-2 and IL-8 mRNAs in esophageal tumors. A representative agarose gel electrophoresis shows the RT-PCR analysis from paired samples, normal mucosa $(\mathrm{N})$ and tumor $(\mathrm{T})$, obtained from selected patients. 3 -actin and PCNA mRNAs were amplified to check for RNA integrity and for the proliferative status of the tissues, respectively.

The reactions were performed in duplicate using Power SYBR ${ }^{\circledR}$ Green PCR Master Mix (Applied Biosystems, USA) and were performed using the ABI PRISM 7500 real-time PCR system (Applied Biosystems). The reaction conditions were: $95^{\circ} \mathrm{C}$ for 3 min followed by 40 cycles of $95^{\circ} \mathrm{C}$ for $1 \mathrm{~min}$ (denaturation) and $60^{\circ} \mathrm{C}$ for $45 \mathrm{sec}$; the melt curve protocol began immediately after amplification and consisted of $1 \mathrm{~min}$ at $55^{\circ} \mathrm{C}$ followed by $80-10-\mathrm{sec}$ steps with a $0.5^{\circ} \mathrm{C}$ increase in temperature at each step. Lack of variation in PCR products and the absence of primer dimers were ascertained from the melt curve profile of the PCR products. The Comparative Ct Method (22) was used to compare changes in gene expression levels. $\beta$-actin was used as endogenous control.

Statistical analysis. Statistical analyses were performed using GraphPad Prism 3.0 (GraphPad Software Incorporated, San Diego, CA, USA). The paired Student's t-test was used to

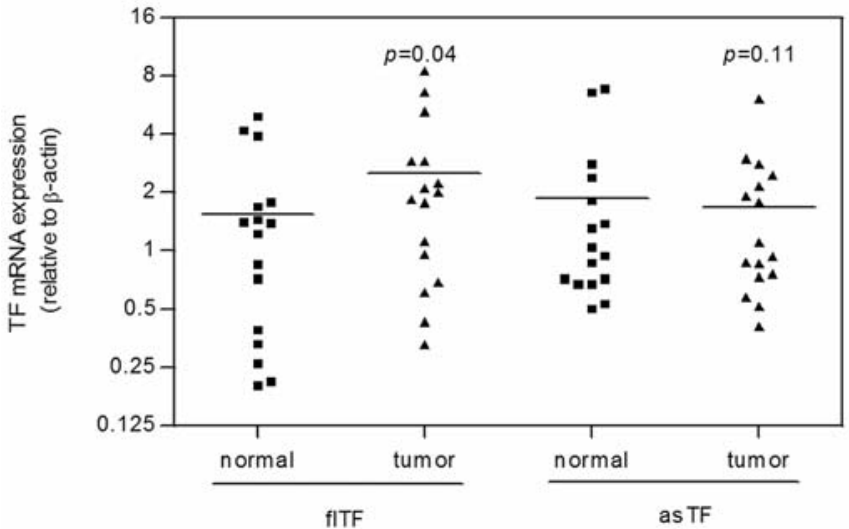

Figure 2. RT-PCR analysis of TF mRNA expression. Full-length (fITF) and alternatively spliced (asTF) TF gene expression was evaluated in normal and tumor samples. Assay conditions are described in Material and methods. Results were normalized to $ß$-actin expression.

determine significant differences between mRNA expression in the tumors and paired normal tissues. A p-value $<0.05$ was considered to be significant.

\section{Results}

Full-length tissue factor (flTF), a 45-kDa transmembrane protein that initiates the coagulation cascade (23), has been demonstrated to be overexpressed in different tumor types (9-12). Therefore, we first employed semi-quantitative RT-PCR to analyze the mRNA levels of the procoagulant form of TF. Fig. 1 shows a representative set of tumors and matched mucosa samples analyzed by RT-PCR. After normalization to $\beta$-actin expression, it was demonstrated that expression levels of flTF gene in tumor samples were significantly increased in relation to the normal mucosa (Fig. 2). We also normalized the expression of this gene to the 

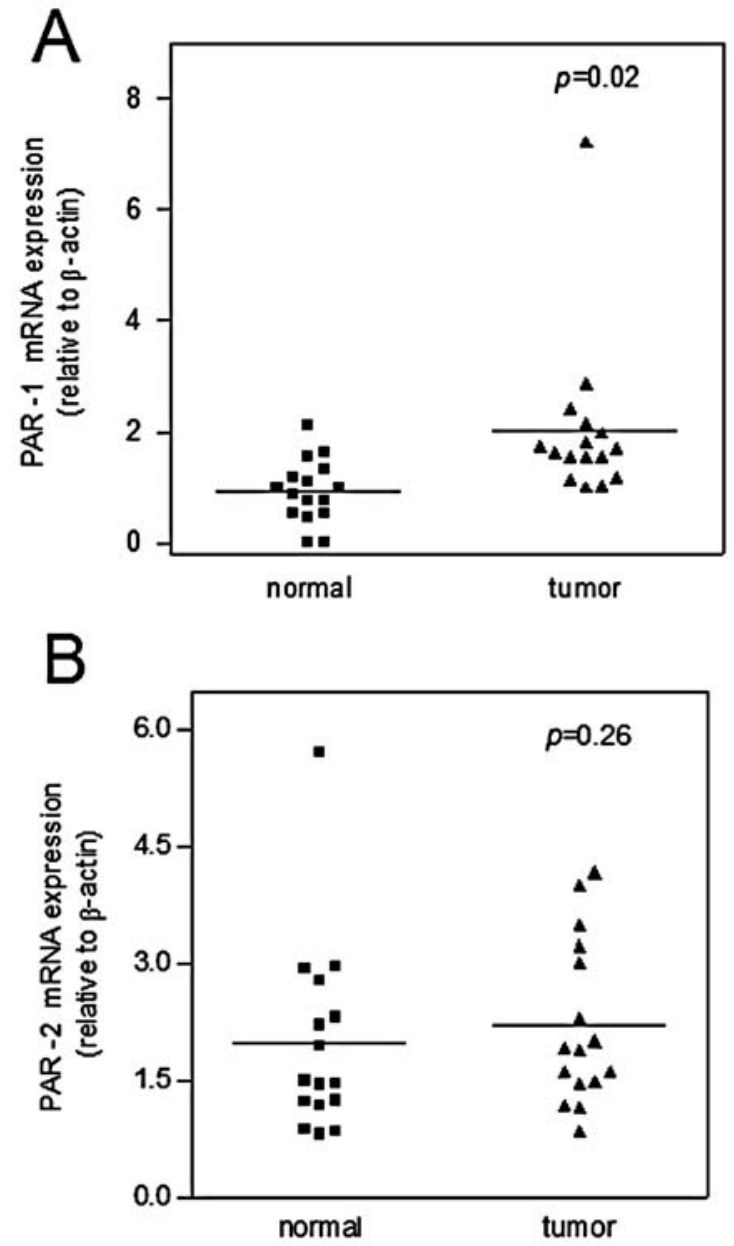

Figure 3. RT-PCR analysis of PAR mRNA expression. (A) PAR-1 and (B) PAR-2 gene expressions were analyzed in normal and tumor samples as described in Material and methods. Results were normalized to $\beta$-actin expression.

expression of PCNA, in order to rule out any discrepancies due to an excessive proliferation of tumor cells (data not shown). However, we did not observe any differences between normalization with $\beta$-actin and PCNA. Therefore, we decided to use the expression of $\beta$-actin to normalize the expression of all genes.

An alternatively spliced form of TF (asTF) has been described as a result of deletion of exon 5 (24). In fact, asTF lacks the transmembrane and cytoplasmic domains observed in flTF, being thus considered a soluble form of this protein. It was recently proposed that asTF is involved in tumor growth and angiogenesis (25). As shown in Fig. 1, both normal and tumor esophageal tissues expressed asTF mRNA, which was identified as an 815 bp product in contrast to a 972 bp product from the flTF transcript. However, Fig. 2 shows that no significant differences in the expression levels of asTF were observed between normal and tumor samples.

Involvement of blood clotting enzymes in tumor progression is intimately related to expression of proteaseactivated receptors (PARs), in particular PAR-1 and PAR-2 (13-15). Thus, we next examined the mRNA expression pattern for both receptors. As seen in Fig. 3, tumor samples exhibited a significant increase in PAR-1 gene expression

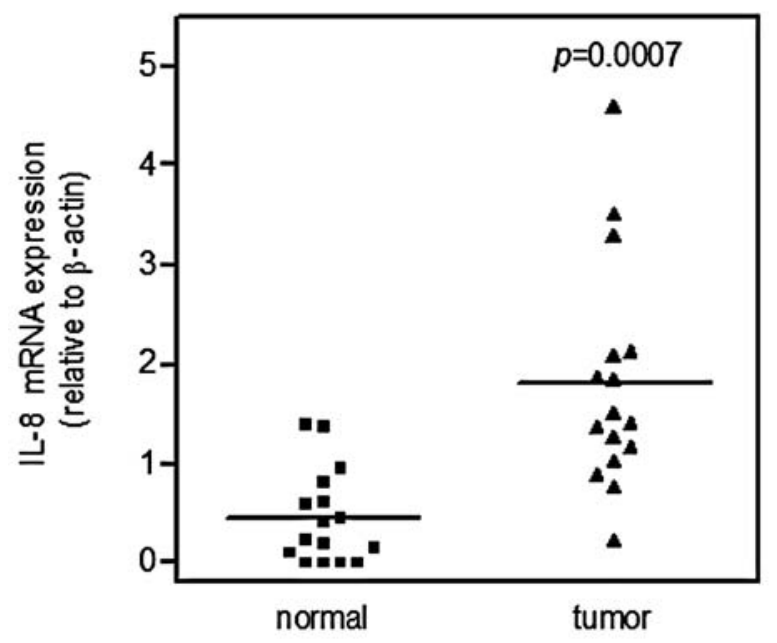

Figure 4. RT-PCR analysis of IL-8 mRNA expression. IL-8 gene expression was evaluated in normal and tumor samples as described in Material and methods. Results were normalized to ß-actin expression.

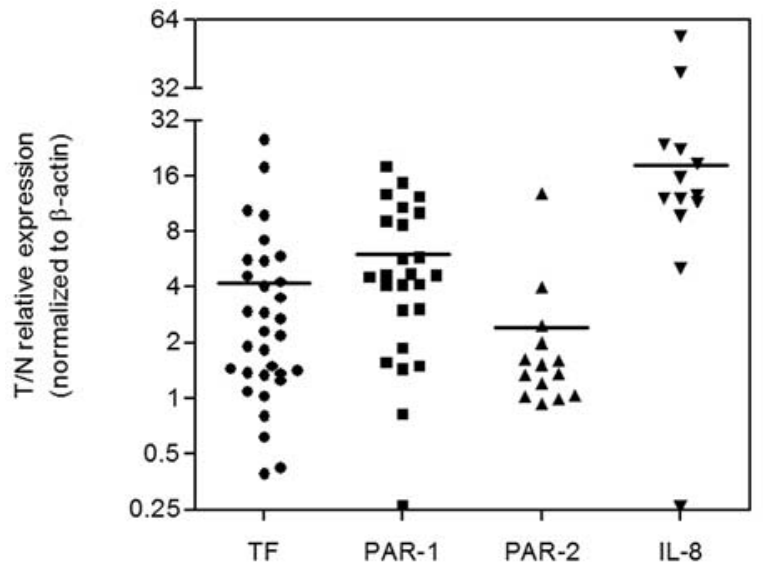

Figure 5. qPCR analysis of TF, PAR-1, PAR-2 and IL-8 mRNA expression. Gene expression was evaluated in normal and tumor samples as described in Material and methods. Results were normalized to ß-actin expression.

in relation to normal tissue. In contract, there was no statistically relevant difference in PAR-2 expression levels.

It was recently reported that ESCC patients present elevated levels of interleukin-8 (IL-8), which correlates with tumor size and tumor dissemination (26). In this context, it has been clearly demonstrated in vitro that IL-8 expression might be up-regulated by either thrombin/PAR-1 or factor VIIa/TF/PAR-2-mediated cascades $(27,28)$. Therefore, we further analyzed the IL-8 mRNA levels in the tissue samples. As demonstrated in Fig. 4, IL-8 expression was not detected in most of the normal tissues but it was very high in tumor samples.

In order to corroborate the results obtained by semiquantitative RT-PCR, a large number of samples were further analyzed by qPCR. Fig. 5 shows that qPCR analyses confirmed the overexpression of TF, PAR-1 and IL-8 in tumor samples in relation to non-tumoral tissues. As expected, quantitative analyses revealed greater differences in the 
expression levels but the general profile previously observed by conventional RT-PCR was very similar.

\section{Discussion}

It has been well documented that blood coagulation is activated in cancer patients, who are very susceptible to developing thrombotic complications (29). Thrombosis has been referred to as a marker of poor prognosis in cancer (30). In this context, the aberrant expression of the clotting initiator protein, tissue factor (TF), has been pointed out as a key determinant for increased blood clotting activation in cancer (8). Recently, White and co-workers found esophageal cancer amongst the five types of cancer at highest risk for developing venous thromboembolism (30). Accordingly, in this study a significant elevation in full-length, procoagulant, TF gene expression was found in esophageal tumor specimens as compared to normal tissues, either by semi-quantitative or quantitative PCR analyses. Expression of flTF was significantly increased in tumor samples, being elevated ( $\mathrm{T} / \mathrm{N}$ expression ratio $>2.0$ ) in $18 / 34$ specimens. This observation parallels with several other studies that demonstrated elevated TF expression in breast, colorectal, hepatocellular and non-small lung cancers among others (9-12).

Expression of TF by tumor cells and subsequent generation of blood clotting enzymes has been intimately related to tumor progression and metastasis. In this regard, a number of pro-tumoral responses have been associated with coagulation enzyme-mediated activation of PARs $(14,15)$. In particular, increased expression of PAR-1 or PAR-2 has been described in several tumor types including breast, prostate, colon and melanoma (16-19). Moreover, Depasquale et al recently reported PAR-1 as a prognostic factor in melanomas which displayed strong correlation with tumor stage (31). Herein, we observed that PAR-1 expression is up-regulated in esophageal tumor samples and was detected in 19/29 patients ( $\mathrm{T} / \mathrm{N}$ expression ratio $>2.0$ ). On the other hand, there was no statistically relevant difference in PAR-2 expression levels, which presented increased rates in 3/20 tumor samples.

Acquisition of a highly vascularized tumor phenotype (angiogenic switch) has been shown to occur during the precancerous stage of human ESCC (32). This process is thought to be coordinated by VEGF, which correlates with histological differentiation, metastasis and survival in ESCC patients $(33,34)$. In this context, Yin et al have demonstrated that PAR-1 mediates oncogenic transformation in tumor cells by a mechanism that includes VEGF production (35). Therefore, it is possible that PAR-1 mediates the production of this angiogenic factor in esophageal cancer.

In addition to VEGF, interleukin-8 (IL-8) is a cytokine that has been strongly associated with angiogenesis as well as with tumor growth $(36,37)$. ESCC patients present increased plasma levels of IL-8, which correlates with tumor size and metastasis (26). In this context, our data demonstrated a dramatic increase in IL-8 gene expression in esophageal tumor samples, being elevated in 17/19 (T/N) samples. In addition, most of the normal tissues showed no IL-8 production which is in accordance with the study of Kitadai et al (32). Production of IL- 8 by tumor cells might be modulated by either PAR-1 or PAR-2, as demonstrated by in vitro studies $(27,28)$. Therefore, it is possible that production of IL-8, as well as other inflammatory mediators (38) by esophageal tumor cells is modulated, at least in part, by PAR receptors.

Taken together, our data demonstrate that TF and PAR-1 gene expression is up-regulated in human esophageal cancer. In this regard, it is possible that blood coagulation proteins play a significant role in this malignant neoplastic disease, which could offer additional strategies for the development of new therapies.

\section{Acknowledgements}

We thank the members of the services of HUPE-UERJ and HC-UNICAMP. This research was supported by Conselho Nacional de Desenvolvimento Científico e Tecnológico (CNPq), Coordenação de Aperfeiçoamento de Pessoal de Nível Superior (CAPES) and Fundação de Amparo à Pesquisa do Estado do Rio de Janeiro Carlos Chagas Filho (FAPERJ).

\section{References}

1. Kamangar F, Dores GM and Anderson WF: Patterns of cancer incidence, mortality, and prevalence across five continents: defining priorities to reduce cancer disparities in different geographic regions of the world. J Clin Oncol 24: 2137-2150, 2006.

2. Ribeiro Pinto LF, Teixeira Rossini AM, Albano RM, Felzenszwalb I, De Moura Gallo CV, Nunes RA and Andreollo NA: Mechanisms of esophageal cancer development in Brazilians. Mutat Res 544: 365-373, 2003.

3. Allen JW, Richardson JD and Edwards MJ: Squamous cell carcinoma of the esophagus: a review and update. Surg Oncol 6: 193-200, 1997.

4. Vizcaino AP, Moreno V, Lambert R, et al: Time trends incidence of both major histologic types of esophageal carcinomas in selected countries, 1973-1995. Int J Cancer 99: 860-868, 2002.

5. Enzinger PC and Mayer RJ: Medical progress: esophageal cancer. N Engl J Med 349: 2241-2252, 2003.

6. Law S and Wong J: The current management of esophageal cancer. Adv Surg 41: 93-119, 2007.

7. Varki A: Trousseau's syndrome: multiple definitions and multiple mechanisms. Blood 110: 1723-1729, 2007.

8. Rak J, Milsom C, May L, Klement P and Yu J: Tissue factor in cancer and angiogenesis: the molecular link between genetic tumor progression, tumor neovascularization, and cancer coagulopathy. Semin Thromb Hemost 32: 54-70, 2006.

9. Kakkar AK, Lemoine NR, Scully MF, Tebbutt S and Williamson RC: Tissue factor expression correlates with histological grade in human pancreatic cancer. Br J Surg 82: 1101-1104, 1995.

10. Nakasaki T, Wada H, Shigemori C, Miki C, Gabazza EC, Nobori T, Nakamura $\mathrm{S}$ and Shiku H: Expression of tissue factor and vascular endothelial growth factor is associated with angiogenesis in colorectal cancer. Am J Hematol 69: 247-254, 2002.

11. Sawada M, Miyake S, Ohdama S, Matsubara O, Masuda S, Yakumaru K and Yoshizawa Y: Expression of tissue factor in non-small-cell lung cancers and its relationship to metastasis. Br J Cancer 79: 472-477, 1999.

12. Poon RT, Lau CP, Ho JW, Yu WC, Fan ST and Wong J: Tissue factor expression correlates with tumor angiogenesis and invasiveness in human hepatocellular carcinoma. Clin Cancer Res 9: 5339-5345, 2003

13. Ossovskaya VS and Bunnett NW: Protease-activated receptors: contribution to physiology and disease. Physiol Rev 84: 579-621, 2004.

14. Rao LV and Pendurthi UR: Tissue factor-factor VIIa signaling. Arterioscler Thromb Vasc Biol 25: 47-56, 2005. 
15. Belting M, Ahamed J and Ruf W: Signaling of the tissue factor coagulation pathway in angiogenesis and cancer. Arterioscler Thromb Vasc Biol 25: 1545-1550, 2005

16. Even-Ram S, Uziely B, Cohen P, Grisaru-Granovsky S, Maoz M, Ginzburg Y, Reich R, Vlodavsky I and Bar-Shavit R: Thrombin receptor overexpression in malignant and physiological invasion processes. Nat Med 4: 909-914, 1998.

17. Liu Y, Gilcrease MZ, Henderson Y, Yuan XH, Clayman GL and Chen Z: Expression of protease-activated receptor 1 in oral squamous cell carcinoma. Cancer Lett 169: 173-180, 2001.

18. Darmoul D, Gratio V, Devaud H, Lehy T and Laburthe M: Aberrant expression and activation of the thrombin receptor protease-activated receptor-1 induces cell proliferation and motility in human colon cancer cells. Am J Pathol 162: 1503-1513, 2003.

19. Ikeda O, Egami H, Ishiko T, Ishikawa S, Kamohara H, Hidaka H, Mita $\mathrm{S}$ and Ogawa M: Expression of proteinase-activated receptor-2 in human pancreatic cancer: a possible relation to cancer invasion and induction of fibrosis. Int J Oncol 22: 295-300, 2003

20. Simão TA, Simões GL, Ribeiro FS, Cidade DA, Andreollo NA, Lopes LR, Macedo JM, Acatauassu R, Teixeira AM, Felzenszwalb I, Pinto LF and Albano RM: Lower expression of p14ARF and p16INK4a correlates with higher DNMT3B expression in human oesophageal squamous cell carcinomas. Hum Exp Toxicol 25: 515-522, 2006.

21. Robottom Ferreira AB, Ribeiro Pinto LF and Albano RM: An optimized reverse transcription-polymerase chain reaction procedure for the amplification of low-copy Cyp2a3 mRNA in rat esophagus. Anal Biochem 319: 323-326, 2003.

22. Schmittgen TD and Livak KJ: Analyzing real-time PCR data by the comparative C(T) method. Nat Protoc 3: 1101-1108, 2008.

23. Gomez K and McVey JH: Tissue factor initiated blood coagulation. Front Biosci 11: 1349-1359, 2006.

24. Bogdanov VY, Balasubramanian V, Hathcock J, Vele O, Lieb M and Nemerson Y: Alternatively spliced human tissue factor: a circulating, soluble, thrombogenic protein. Nat Med 9: 458-462, 2003.

25. Signaevsky M, Hobbs J, Doll J, Liu N and Soff GA: Role of alternatively spliced tissue factor in pancreatic cancer growth and angiogenesis. Semin Thromb Hemost 34: 161-169, 2008.

26. Krzystek-Korpacka M, Matusiewicz M, Diakowska D, Grabowski K, Blachut K, Konieczny D, Kustrzeba-Wojcicka I, Terlecki $G$ and Banas T: Elevation of circulating interleukin- 8 is related to lymph node and distant metastases in esophageal squamous cell carcinomas - implication for clinical evaluation of cancer patient. Cytokine 41: 232-239, 2008
27. Hjortoe GM, Petersen LC, Albrektsen T, Sorensen BB, Norby PL, Mandal SK, Pendurthi UR and Rao LV: Tissue factor-factor VIIa-specific up-regulation of IL-8 expression in MDA-MB231 cells is mediated by PAR-2 and results in increased cell migration. Blood 103: 3029-3037, 2004.

28. Liu J, Schuff-Werner P and Steiner M: Thrombin/thrombin receptor (PAR-1)-mediated induction of IL-8 and VEGF expression in prostate cancer cells. Biochem Biophys Res Commun 343: 183-189, 2006

29. Lip GY, Chin BS and Blann AD: Cancer and the prothrombotic state. Lancet Oncol 3: 27-34, 2002.

30. White $\mathrm{RH}$, Chew $\mathrm{H}$ and Wun T: Targeting patients for anticoagulant prophylaxis trials in patients with cancer: Who is at highest risk? Thromb Res 120 (S2): 29-40, 2007.

31. Depasquale I and Thompson WD: Prognosis in human melanoma: PAR-1 expression is superior to other coagulation components and VEGF. Histopathology 52: 500-509, 2008.

32. Kitadai Y, Onogawa S, Kuwai T, Matsumura S, Hamada H, Ito $\mathrm{M}$, Tanaka S, Yoshihara $\mathrm{M}$ and Chayama K: Angiogenic switch occurs during the precancerous stage of human esophageal squamous cell carcinoma. Oncol Rep 11: 315-319, 2004.

33. Noguchi T, Takeno S, Shibata T, Uchida Y, Yokoyama S and Müller W: VEGF-C expression correlates with histological differentiation and metastasis in squamous cell carcinoma of the esophagus. Oncol Rep 9: 995-999, 2002.

34. Möbius C, Freire J, Becker I, Feith M, Brücher BL, Hennig M, Siewert JR and Stein HJ: VEGF-C expression in squamous cell carcinoma and adenocarcinoma of the esophagus. World J Surg 31: 1768-1774, 2007

35. Yin YJ, Salah Z, Maoz M, Ram SC, Ochayon S, Neufeld G, Katzav $\mathrm{S}$ and Bar-Shavit R: Oncogenic transformation induces tumor angiogenesis: a role for PAR1 activation. FASEB J 17: 163-174, 2003

36. Yuan A, Chen JJ, Yao PL and Yang PC: The role of interleukin-8 in cancer cells and microenvironment interaction Front Biosci 10: 853-865, 2005.

37. Strieter RM, Burdick MD, Mestas J, Gomperts B, Keane MP and Belperio JA: Cancer CXC chemokine networks and tumour angiogenesis. Eur J Cancer 42: 768-778, 2006.

38. Francischetti IM, Seydel KB and Monteiro RQ: Blood coagulation, inflammation, and malaria. Microcirculation 15 . 81-107, 2008. 